\title{
Review Article \\ Circadian System and Melatonin Hormone: Risk Factors for Complications during Pregnancy
}

\author{
F. J. Valenzuela, ${ }^{1,2}$ J. Vera, ${ }^{1,2}$ C. Venegas, ${ }^{1,2}$ F. Pino, ${ }^{1}$ and C. Lagunas ${ }^{1,2}$ \\ ${ }^{1}$ Department of Basic Sciences, Universidad del Bío-Bío, Campus Fernando May, Avenida Andres Bello s/n, Chillán, Chile \\ ${ }^{2}$ Grupo de Ciencias Biotecnológicas, Basic Sciences Department, Universidad del Bío-Bío, Avenida Andres Bello s/n, Chillán, Chile \\ Correspondence should be addressed to F. J. Valenzuela; fvalenzuela@ubiobio.cl
}

Received 29 August 2014; Accepted 8 February 2015

Academic Editor: Enrique Hernandez

Copyright (c) 2015 F. J. Valenzuela et al. This is an open access article distributed under the Creative Commons Attribution License, which permits unrestricted use, distribution, and reproduction in any medium, provided the original work is properly cited.

\begin{abstract}
Pregnancy is a complex and well-regulated temporal event in which several steps are finely orchestrated including implantation, decidualization, placentation, and partum and any temporary alteration has serious effects on fetal and maternal health. Interestingly, alterations of circadian rhythms (i.e., shiftwork) have been correlated with increased risk of preterm delivery, intrauterine growth restriction, and preeclampsia. In the last few years evidence is accumulating that the placenta may have a functional circadian system and express the clock genes Bmal1, Perl-2, and Clock. On the other hand, there is evidence that the human placenta synthesizes melatonin, hormone involved in the regulation of the circadian system in other tissues. Moreover, is unknown the role of this local production of melatonin and whether this production have a circadian pattern. Available information indicates that melatonin induces in placenta the expression of antioxidant enzymes catalase and superoxide dismutase, prevents the injury produced by oxidative stress, and inhibits the expression of vascular endothelial growth factor (VEGF) a gene that in other tissues is controlled by clock genes. In this review we aim to analyze available information regarding clock genes and clock genes controlled genes such as VEGF and the possible role of melatonin synthesis in the placenta.
\end{abstract}

\section{Introduction}

Pregnancy is a complex and well-regulated temporal event in which several steps are finely orchestrated including implantation, decidualization, placentation, and partum [1]. The chronological transitions are critical for a normal pregnancy and any temporary alteration may have detrimental effects for fetal development and/or maternal health [2-4]. The placenta is the unit of communication and exchange between mother and fetus. This organ is in charge of bidirectional transference and metabolism of hormones, nutrients, and gases (oxygen/ $\mathrm{CO}_{2}$ ) [5]. The major site of complication in pregnancy is the placenta and the main cause of development of obstetric syndrome is the placentation [6]. The impaired placentation causes spontaneous abortion, preeclampsia, preterm birth, and placental abruption [7]. Moreover, placenta mediates the maternal-fetal interaction in the regulation of glucocorticoids, human placental lactogen (hPL), human chorionic gonadotropin (hCG), and progesterone and estriol, among others $[5,8]$. In this regard, hormonal production and activity is regulated by a circadian system, which, in fact, is composed by a family of genes named "clock genes" (Bmall, Clock, Perl-3, and Cryl-2) [9].

\section{Circadian Rhythms and Pregnancy}

The circadian time-keeping system is actively engaged in the maintenance of normal physiology, not only in adults, but also during development [10]. Within an individual, the peak and trough of the rhythms for different physiological variables occurs at different clock times. For instance, in humans under normal light-dark condition, cortisol peaks at $08 \mathrm{~h}$, while temperature peaks at $14-17 \mathrm{~h}$, and melatonin at $02 \mathrm{~h}$ [11]. Similarly, during normal pregnancy different circadian rhythm are observed in the mother such as temperature [12, 13], leukocytes count, blood pressure [13], circadian pattern of weight gain [14], rhythms of uterine contraction, blood flow [15], and intra-amniotic fluid pressure $[5,15]$. The final output of the circadian system during pregnancy is the labor. Humans and monkeys (diurnal animals) show a peak 
in the second middle of the night and early in the morning $[3,16,17]$. The rat and mice (nocturnal animals) show a time birth in the afternoon or final hours of the day [18, 19]. An important factor during the pregnancy is photoperiod, and light exposition during night hours (inhibition of melatonin production) is able to modify the hours of labor in monkeys and rats $[18,20]$. At level of fetus, circadian rhythms of fetal heart rate and tachycardia are observed in twin pregnancy, showing a peak during light hours [21], showing that both the mother and the fetus have circadian rhythms.

Placenta during the pregnancy has important function of being in charge of bidirectional transference and metabolism of hormones, nutrients, and gases (oxygen $/ \mathrm{CO}_{2}$ ) [5]. Some hormones produced by placenta show a circadian rhythm such as human chorionic gonadotropin (hCG) showing a peak at $12-15 \mathrm{~h}[8,22,23]$. Progesterone and the products of aromatase from placenta which convert dehydroepiandrosterone sulphate (DHES) to estriol and estradiol [5] and placental lactogen show a circadian pattern in junctional and labyrinthine zones in the rat placenta [24].

The phase relation between the circadian rhythms of different physiological variables in the $24 \mathrm{~h}$ cycles generates an internal temporal order $[25,26]$, and recent data show that alterations of circadian rhythms correlated to increased susceptibility to cancer in humans [27]. In addition, it has been reported that incidence of breast cancer increases significantly in women working in shifts, being higher among individuals who spend more years and hours per week working at night [28]. In this sense, during human pregnancy several reports suggest alterations of circadian rhythms are correlated to increased susceptibility to pregnancy disease and a meta-analysis published by Bonzini et al. (2011) showed the impacts of shiftwork in those women [4]. Thus, shiftwork was associated with an increased risk of small for gestational age $(<10$ th percentile) and low birth weight and reported eleven studies showing elevated risk for preterm birth [4]. In animal, pregnant rats exposed to light-dark cycle that mimics shiftwork showed an increase of fat weight and changes in peak hours of plasmatic glucose and leptine in three-monthold offspring [29].

In mammals, circadian rhythms are commanded by a central clock located in the Suprachiasmatic Nucleus of the Hypothalamus (SCN) acting on peripheral circadian clocks located in almost every tissue of the body, for example, in the adrenal gland [30]. In both the SCN and peripheral tissues, the circadian oscillation depends on a transcription/translation feedback loop of a group of genes collectively named "clock genes." This family of clock genes include the transcription factors BMAL1 and CLOCK; the proteins encoded by genes Perl-3, Cryl-2 and the enzyme casein kinase 1 epsilon (CK1ع) [31] (see Figure 1). The mutation of any of the clock genes causes severe disruptions in circadian rhythms [32]. The heterodimer composed of CLOCK-BMAL1 protein is a positive regulator and binds to the E-box sequences (CACGTG) of the promoters of Per and Cry, inducing their expression. The negative regulator is a complex of the proteins PER and CRY which translocate to the nucleus and by protein-protein interaction with CLOCK-BMAL1 inhibits the transcription of Per and Cry. Translocation to the nucleus
PER and CRY requires the formation of a complex with CK1 1 and provides a delay in the system to achieve a period of $24 \mathrm{~h}$ [33]. Clock genes are expressed in multiple tissues: heart, liver, kidney, pancreas, muscle, pars tuberalis, adrenal gland, and isolated cells such as fibroblasts and cardiomyocytes [30, 3441].

Circadian clock genes are expressed in the placenta of rats and mice [42,43] and in the cell line of human trophoblast [44] previously stimulated by serum shock, a potent stimulator of the circadian system such as what has been described in fibroblast [45], immortalized human breast epithelial cell [46], or hepatoma cells [47]. The circadian expression of two genes potentially controlled by clock genes has been also shown in the placenta, the vascular endothelial growth factor (VEGF), and placental lactogen (PL-II). Thus, in the cell line of human trophoblast stimulated with serum shock, the VEGF is expressed with a circadian pattern [44]. Besides in culture of rat placenta stimulated by serum shock, a circadian rhythm of PL-II expression reaching a peak at 04:00 hrs in the junctional zone and at 16:00 hrs in labyrinth zones has been showed [24].

In humans, alterations in the levels of VEGF and human PL (hPL-II) proteins have been proposed as risk markers for preeclampsia or placental dysfunction [48-50] and we speculate that the chronodisruption might be part of pathophysiological process during pregnancies diseases. The vascular endothelial growth factor A (VEGF-A) has been related with occurrence of pregnancy pathologies such as preeclampsia $[48,51]$. VEGF-A is a protein that is under control of the complex CLOCK-BMAL. Thus, the promoter of VEGF has four putative E-box elements (CANNTG) to respond to clock genes, showing a circadian pattern of expression in implanted tumor cell with a peak during light hours [52]. The in vitro transcription of VEGF cotransfected with CLOCK-BMAL increases the level of VEGF protein [52]. On the other hand, the transient expression of Per2 and Cryl inhibits the expression of VEGF [52]. In vivo experiments have showed that implanted tumor cells in mice are subordinated to SCN of the host animal. These cells show circadian rhythms of expression of clock genes and VEGF, observing a peak for the latter during the light hours, in a pattern similar to that observed for Bmall [52]. Considering that both reduced expression and activity of VEGF in the placenta [51] and altered circadian rhythms are associated with pathologies of pregnancy $[4,53]$, we could speculate that the circadian expression of clock genes would be controlling many placental functions in both normal and pathological placenta. This assumption would be difficult to test in human being; therefore investigation should include culture cell or animal models.

Nevertheless, an important question is whether in the culture of fresh human placenta, the clock gene expression is maintained as in vivo condition (i.e., circadian peripheral oscillator). In regard, we demonstrated the expression of the clock genes Bmall and Per2 during 36 hours in explant cultures of the adrenal gland without stimulation of serum shock, suggesting that the adrenal gland is a peripheral oscillator [30]. Whether the placenta contains a peripheral clock able to sustain an oscillation in vitro in absence of 


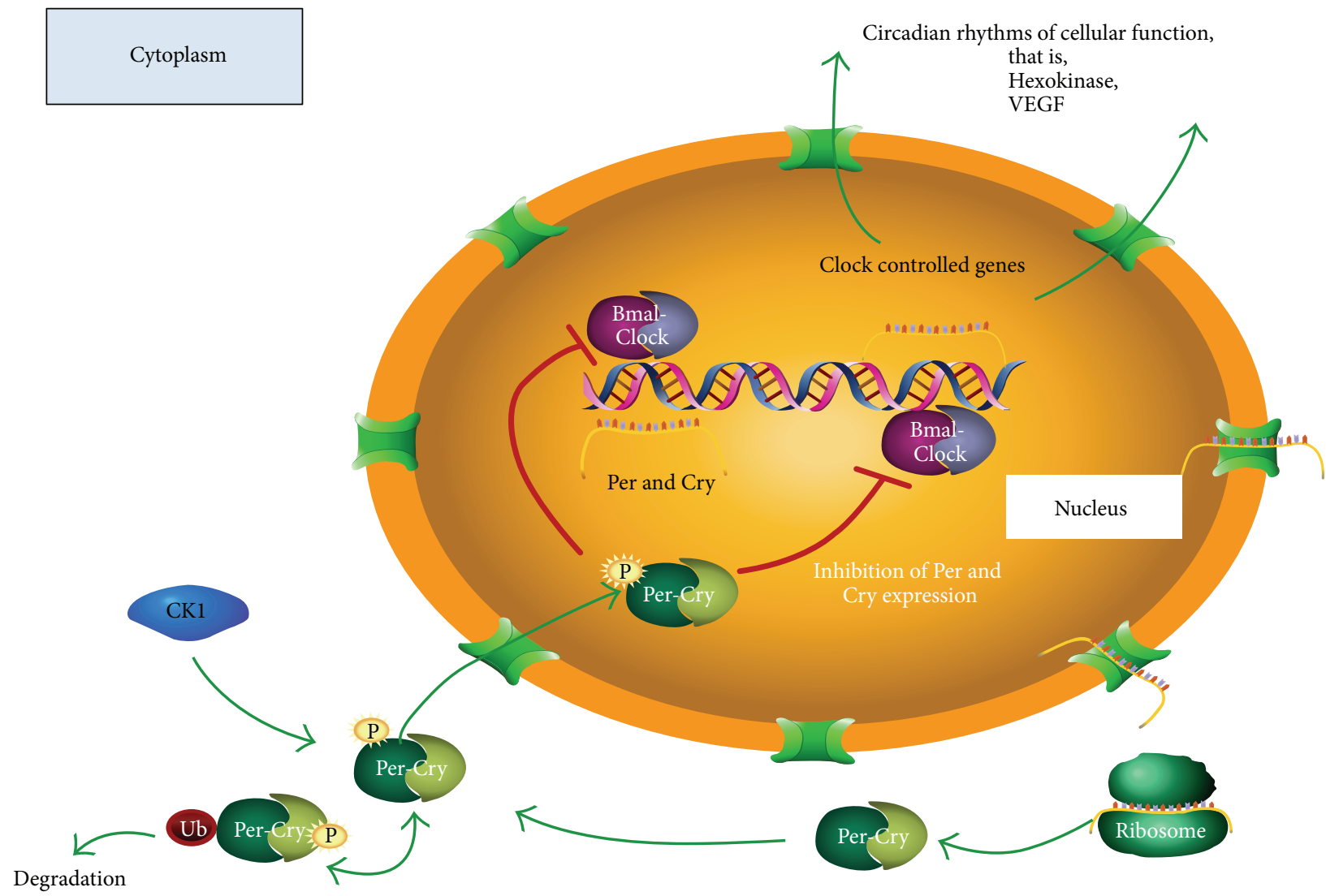

Figure 1: Molecular Circuit of Circadian Oscillator. See details in the text. Positive regulation of clock genes Bmall and Clock stimulate promoter of negative regulators Per 1-2, Cry 1-2 and controlled clock genes Hexokinase and VEGF.

synchronizing stimuli is unknown. However, Frigato et al. (2009) showed that the circadian expression of Per2 is stimulated by serum shock in culture of trophoblast [44], suggesting that placental cell in culture might maintain the circadian oscillation observed in vivo.

In vivo, oscillation of clock genes in some peripheral organs requires the SCN. Guo et al. (2006) demonstrated in hamsters that oscillatory expression of the clock genes Per1, Per2, and Bmall in the heart, liver, kidney, renal cortex, adrenal medulla, muscle, and spleen is eliminated by ablating the SCN [54]. Transplantation of SCN restored the circadian oscillation of clock genes only in the liver and kidney, suggesting that the synchronizing signal from the SCN to the other organs involves neural pathways. These could include the autonomic nervous system or corticosterone and melatonin rhythms that are not restored by SCN transplants [54]. Since the placenta is not innervated but expresses melatonin receptors [55], we believe that melatonin could regulate the expression of clock genes in the placenta.

\section{Melatonin and the Placenta}

The pineal gland synthesizes melatonin, a lipophilic indoleamine hormone, increasing immediately in response to light-off. This increase gives chronobiotic information to the body for its circadian organization [11]. The extension of melatonin during the night is directly proportional to photoperiod (winter or summer), which in turn may modulate the gonadotropin axis and the time of mating sheep $[35,56]$. A second function proposed for melatonin is as homeostatic hormone, regulating several aspects of fetal physiology. For instance, during the pregnancy, maternal melatonin provides a chronobiotic signal for the fetus and also plays a role in the development and maintenance of the fetal adrenal function under conditions suitable for fetal life, an effect that may also involve other fetal systems as shown in fetal sheep [9]. A third function of melatonin in placenta is to modulate the redox status, via both direct scavenger activity for radical species such as hydroxyl, alkoxyl, peroxyl, and nitric oxide (NO) $[11,57,58]$, or regulating the expression of antioxidant enzymes such as catalase and manganese superoxide dismutase [59]. Additionally, in adult tissues melatonin has been shown to increase the expression of several genes such as Bax, p53, p21-27, caspases 3, 8, and 9 [60], NeuroD1, Pbef/Nampt, Hif1 $\alpha$ [61], SGK, Nf $\kappa$ bia, DNAdamage-inducible transcript 4, C/EBP- $\delta$, pdk4, Ets-1, HSP [62], HOXA4, FOXO1A, GTFIIF1, PPAR $\delta$, and TCEB3 [63] or decrease the expression of genes Bax, Bcl-2 [64]; P450 $7 \alpha$ (CYP7B) [65]; metalloproteinase 9, 3 (MMP-9, MMP-3) [66]; heat shock proteins HSP [62]; ZNF33A and PHF15 [63]. Moreover, we have found that melatonin inhibited the expression of Perl, Bmall, and PGCl $\alpha$ in response to 


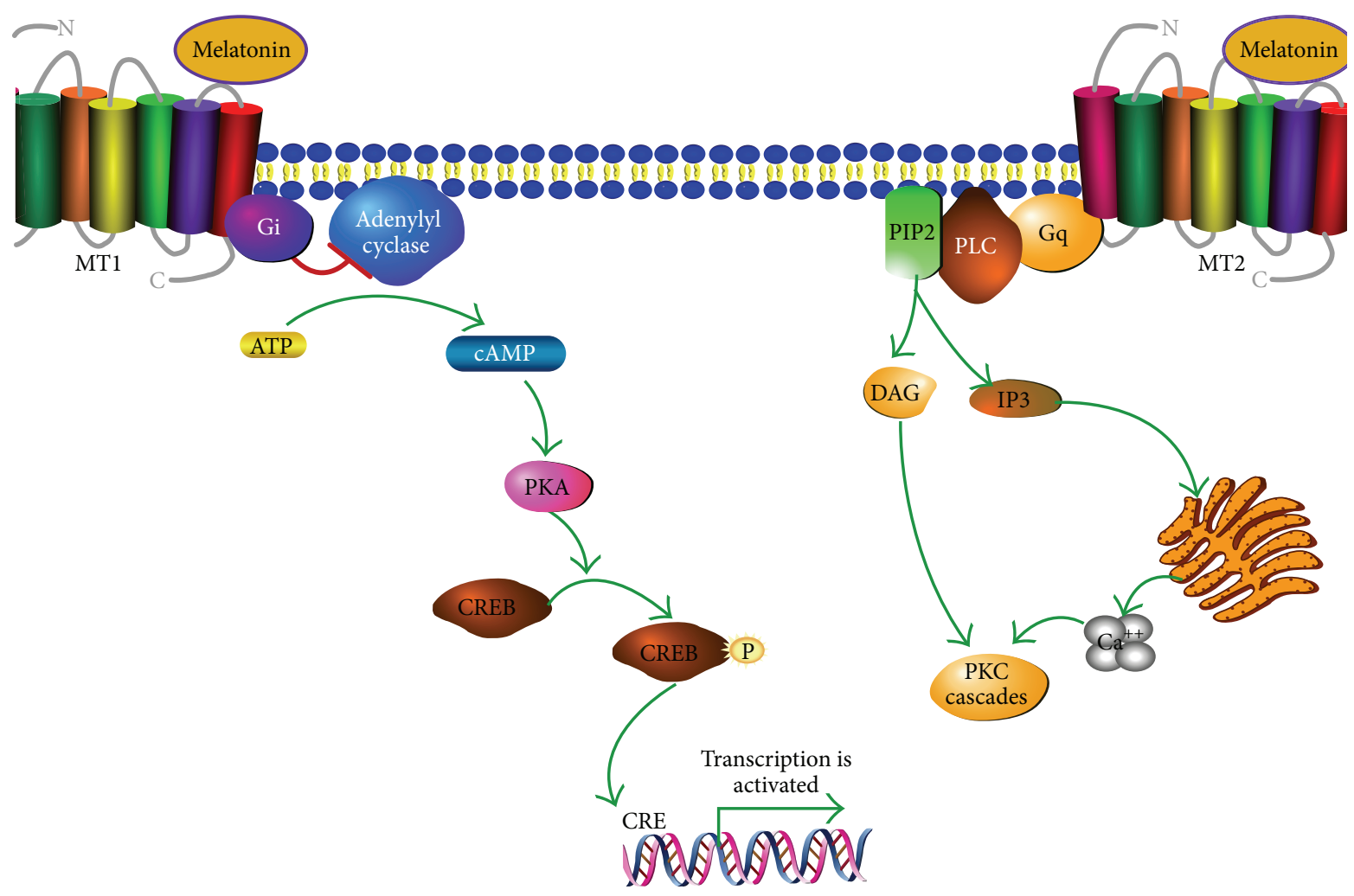

FIGURE 2: Signaling of MT1 and MT2. Both are G protein-coupled receptors. MT1 is associated with Gi protein and inhibition of adenylyl cyclase. MT2 receptor is associated with PKC stimulation and increase of calcium associated with IP3 (for details see Dubocovich et al. [11]).

adrenocorticotropin (ACTH) in humans and sheep [38, 67], strongly suggesting a loop of regulation between melatonin production and clock genes expression.

Melatonin acts through membrane receptors (see Figure 2), although some effects of melatonin could be mediated by binding to endogenous ligand, the orphan nuclear hormone receptor superfamily RZR/ROR [68]. There are two melatonin membrane receptors named MT1 and MT2. Both are G protein-coupled receptors. Thus, MT1 is associated with (i) Gi and inhibition of adenylyl cyclase with decrease of cAMP, (ii) stimulation of potassium channels, and (iii) increase of $\mathrm{Ca}^{2+}$ via phospholipase $\mathrm{C}$ (PLC), whereas the MT2 receptor is associated with (a) Protein Kinase C (PKC) stimulation or (b) increase of calcium associated with $\mathrm{IP}_{3}$. Melatonin receptors MT1 and MT2 are present in many tissues $[11,69]$ although their function is not quite understood. However, their participation has been described in several mechanisms as indicated below.

3.1. Chronobiotic and Homeostatic Effects of Melatonin. In vivo treatment (2 hours) with melatonin increases the expression of Cry-2 in rat pars tuberalis [36] and decreases in the amplitude of the peak of Perl, suggesting an inhibitory effect of melatonin on this gene expression. In sheep, in which the secretion of melatonin was abolished by exposure to continuous light, expression of the clock genes Per 1-2 and Bmall continued in the pars tuberalis. However, melatonin treatment at any point in the day for a period of 3 hours induced mRNA expression of Cry-1 and inhibited the expression of Per 1-2 and Bmall, effects that were not observed in the SCN [70]. In capuchin monkey, adrenal explants maintain an oscillatory expression of Bmall and Per2 for at least 36 hours in culture, and the treatment with melatonin decreased the expression of Bmall and Per2 [30]. Similar effects have been shown in the rat fetal adrenal in culture [40] and recently we detected that melatonin inhibit the expression of Perl and Bmall in response to ACTH in newborn sheep and human adrenal gland $[38,67]$. Moreover, melatonin via melatonin receptor MT1 and MT2 can modify the levels of pro- or antiapoptotic proteins such as Bax and Bcl-2 in human neuroblastoma cells [64]; similarly in placenta, treatment with $10 \mu \mathrm{M}$ of melatonin in villous trophoblast cells increases the survival via inhibition of loss of mitochondrial membrane potential and stimulating the formation of complex Bax/Bcl2 (intrinsic via), expression of caspase-9, and the activation of ROCK1 [71].

3.2. Antioxidant Effects of Melatonin. Melatonin has a potent scavenger activity over hydroxyl, alkoxyl, and peroxyl radicals, as well as over species derived from nitrogen such as nitric oxide (NO) radicals [11, 57, 58]. In this regard, Milczarek et al. (2010) reported in placentas obtained after delivery a potent antioxidant effect of melatonin, specifically 
preventing the NADPH and iron dependent lipid peroxidation in the mitochondria [72]. Moreover, in studies of fetal growth restriction in animal model by placental ischemia, increased placental level of 8-hydroxy-2-deoxyguanosine has been detected (8-OHdG, i.e., a marker of a marker of oxidative DNA damage) [73] compared with controls. Both growth restriction and DNA damage were reverted when the rats received an oral dose of melatonin. Similarly, in rat undernourished pregnancy at day 20 of gestation, the fetal biometry showed lower values for fetal body weight and fetal body/placental weight ratio; moreover a tendency to a higher value of melatonin in maternal and fetal plasma is observed. Placentas from undernourished pregnancy showed no changes in the expression of antioxidant enzymes Mn-SOD, catalase, and GPx-1. However, the melatonin treatment during the pregnancy restores the placental efficiency at level of fetal body weight and fetal body/placental weight and induces the protein expression of Mn-SOD and catalase [59], suggesting that melatonin could be a candidate for protection/treatment of diseases characterized by placental ischemia such as intrauterine growth restriction, preeclampsia [73], or undernourished pregnancy [59]. Indeed, recent evidences have described that melatonin administration improved fetal-placental hemodynamic [74] and increased umbilical blood flow, an effect associated with "NO-dependent mechanisms" [75], as what occurs in cotyledonary placental arteries, via increased sensitivity to vasorelaxation agents such as bradykinin and lower contractile response to noradrenaline [76]. Additionally, melatonin administration reverted the increment of lipid peroxidation in the placenta and liver of mother and fetus exposed to cholestasis of pregnancy [77]. Interestingly, in human it has been described that oral melatonin administration increased glutathione peroxidase (GSH-Px) in the placenta of Japanese women with pregnancies of 7 and 9 weeks of gestation [78].

Protective effects of other antioxidant agents on fetal growth and development strongly support the protective effects of melatonin in adverse pregnancy being due to its antioxidant rather than antioxidant-independent properties, for example, developmental programming of cardiovascular dysfunction by prenatal hypoxia and oxidative stress.

3.3. Melatonin and Vascular Remodeling. In rats, it has been described that melatonin regulate the levels of NO and VEGF in the nervous system, that is, in the choroid plexus, cerebellum, periventricular white matter, and hippocampus [79-82]. Moreover, melatonin treatment for short or long periods of time inhibits the endogenous expression of VEGF and hypoxia induced factor 1 alpha (HIF-1 $\alpha$ ) in tumor cells [83]. In addition, melatonin induces the expression of VEGF and matrix metalloproteinase- (MMP-) 2 in extrapineal tissues such as gastric mucosa [66]. Also melatonin increases bone defect repair in rabbits [84]. All these indirect evidences suggest that melatonin may control vessel formation. Nevertheless, other reports have showed reduced tumor angiogenesis in mice treated with melatonin [85], as well as reduced human umbilical vein endothelial cell proliferation/migration induced by VEGF $[86,87]$.

\section{Extrapineal Production of Melatonin: The Placenta}

The critical enzymes for the synthesis of melatonin are arylalkylamine N-acetyltransferase (AA-NAT) and hydroxyindole O-methyltransferase (HIOMT). These enzymes are expressed in the major site of synthesis of melatonin, in the pineal gland with a circadian pattern of activity for AANAT [11], and in the human placenta [88]. Therefore, the human placenta can be considered as an extrapineal source of melatonin similar to retina [89] and lymphocytes [90]. In this regard, expression (mRNA and protein) of AA-NAT and HIOMT has been detected in both cell line of human placental trophoblasts and human term placentas [71, 88, 91]. In addition, other reports have described the presence of MT1 and MT2 in total human placenta [55] or placental endothelial cells [88]. Interestingly, MT1 is expressed at high levels in the junctional zone during day hours (16:00 hrs) and in the labyrinth during night hours (04:00 hrs) in mice [24].

We do not know whether the production of melatonin in the human placenta changes with the hours of the day. Interestingly, in normal pregnancies, serum levels of melatonin increase progressively until 32 weeks of gestation and decrease prior to delivery reaching the lowest levels at 2 days postpartum [92-95]. Moreover, the level of melatonin is higher in human twins pregnancies [92], as well as it is correlated with the number of pups in animal models [94], suggesting a relationship between placental volume and melatonin level. Nevertheless, in human pregnancies associated with placental alteration, the maternal circadian production of melatonin is lost and it is associated with diminished levels of melatonin. For example, circadian alteration has been observed in humans at the level of diastolic blood pressure, plasma concentration, and circadian production of melatonin during preeclampsia. After pregnancy, these women showed a normal circadian diastolic blood pressure but maintained altered rhythm for melatonin [53]. In contrast to humans, AA-NAT is not expressed in the placenta of rats, and an increase of maternal melatonin is a consequence of placental factor released into the circulation, which would stimulate the maternal pineal gland [94].

Although melatonin has multiple effects on placental function, including induction of the expression in undernourished pregnancy of antioxidant enzymes such as superoxide dismutase (Mn-SOD) and catalase [59], prevention of oxidative stress-mediated injury during placental ischemia [73], inhibition of hCG release in trophoblast cells [91], and inhibition of formation of proapoptotic complex [71], the role of this local production in the human placenta is not well understood and opens the possibility of autocrine, intracrine, or paracrine effects. Although there are no direct evidences, other studies using lymphoid cells, which express the enzymes NAT and HIOMT and produce 5-fold more melatonin than pineal gland, have described that melatonin produced locally has a minor effect on melatonin serum level but has a local role incrementing the IL-2 production [90]. This last effect was inhibited by luzindole and CGP 55644, an antagonist of membrane and nuclear receptors of melatonin [96]. Then, it is feasible that melatonin can be modulating 


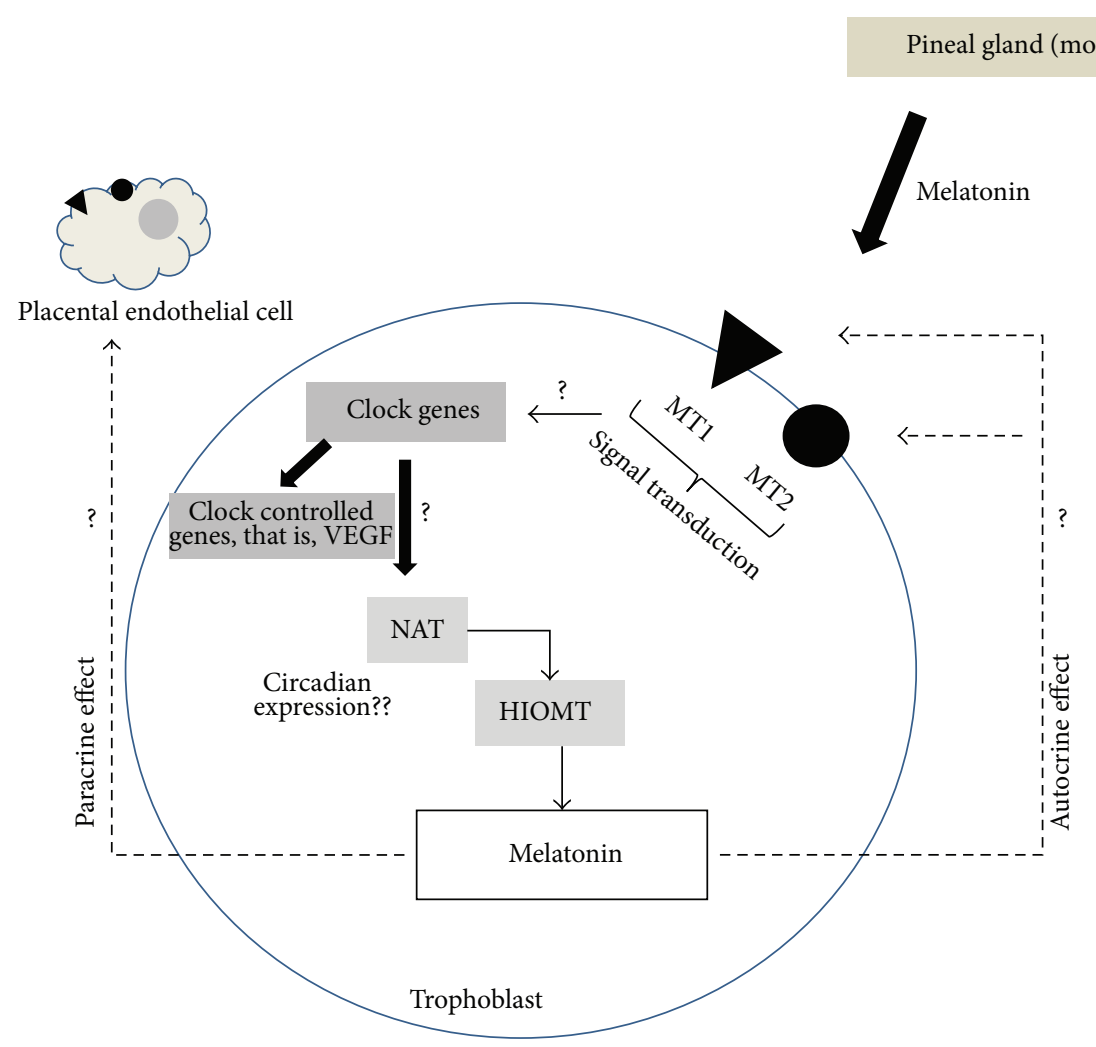

FIGURE 3: Autocrine and paracrine effects of melatonin over circadian system and enzyme of synthesis of melatonin localized in trophoblast and endothelial cells.

the circadian system in the placenta, see Figure 3, producing changes in clock genes that may control VEGF or enzymes NAT and HIOMT. We encourage the scientific community with this idea.

\section{Conclusion}

Participation of the circadian regulatory system has been described as a feedback regulatory loop where melatonin is downregulating the clock genes. In turn, clock genes upregulate the expression of output genes such as VEGF, SOD, NAT, and HIOMT. Current evidences describe that the placenta is a nonpineal organ, which synthesizes melatonin, and the activity of this organ is regulated by a circadian system. Moreover, an impaired circadian system is associated with an altered production of melatonin; however, the effect of this alteration on clock gene expression or output genes (VEGF) has not been described. We believe that circadian system and melatonin are a keystone molecule in the placental physiology, but more studies are necessary in order to test this idea. In this regard, we propose that melatonin may control clock gene expression (Bmal1, Perl-3, Cryl-2, and Clock) and output genes (VEGF) during normal pregnancies.

\section{Glossary}

BMAL1: Aryl hydrocarbon receptor nuclear translocator-like
CLOCK: Circadian locomotor output cycles kaput

PER: $\quad$ Homolog of period, Drosophila

E-BOX: Promoter sequence for binding of clock-bmall complex (CACGTG)

CREB: cAMP response element-binding protein

PGC1 $\alpha$ : Peroxisome proliferator-activated receptor-gamma, coactivator $1 \alpha$.

\section{Conflict of Interests}

None of the authors have a conflict of interests.

\section{Acknowledgment}

This paper received funding Conicyt 79112027 (Chile).

\section{References}

[1] J. Cha, X. Sun, and S. K. Dey, "Mechanisms of implantation: strategies for successful pregnancy," Nature Medicine, vol. 18, no. 12, pp. 1754-1767, 2012.

[2] P. H. Andraweera, G. A. Dekker, and C. T. Roberts, "The vascular endothelial growth factor family in adverse pregnancy outcomes," Human Reproduction Update, vol. 18, no. 4, Article ID dms011, pp. 436-457, 2012.

[3] J. Olcese, "Circadian aspects of mammalian parturition: a review," Molecular and Cellular Endocrinology, vol. 349, no. 1, pp. 62-67, 2012. 
[4] M. Bonzini, K. T. Palmer, D. Coggon, M. Carugno, A. Cromi, and M. M. Ferrario, "Shift work and pregnancy outcomes: a systematic review with meta-analysis of currently available epidemiological studies," BJOG, vol. 118, no. 12, pp. 1429-1437, 2011.

[5] M. Serón-Ferré, C. A. Ducsay, and G. J. Valenzuela, "Circadian rhythms during pregnancy," Endocrine Reviews, vol. 14, no. 5, pp. 594-609, 1993.

[6] W. P. Mutter and S. A. Karumanchi, "Molecular mechanisms of preeclampsia," Microvascular Research, vol. 75, no. 1, pp. 1-8, 2008.

[7] R. Romero, J. P. Kusanovic, T. Chaiworapongsa, and S. S. Hassan, "Placental bed disorders in preterm labor, preterm PROM, spontaneous abortion and abruptio placentae," Best Practice and Research: Clinical Obstetrics and Gynaecology, vol. 25, no. 3, pp. 313-327, 2011.

[8] S. Rotmensch, C. Celentano, N. Elliger et al., "Diurnal variation of human chorionic gonadotropin $\beta$-core fragment concentrations in urine during second trimester of pregnancy," Clinical Chemistry, vol. 47, no. 9, pp. 1715-1717, 2001.

[9] M. Seron-Ferre, G. J. Valenzuela, and C. Torres-Farfan, "Circadian clocks during embryonic and fetal development," Birth Defects Research Part C: Embryo Today: Reviews, vol. 81, no. 3, pp. 204-214, 2007.

[10] M. Serón-Ferré, N. Mendez, L. Abarzua-Catalan et al., "Circadian rhythms in the fetus," Molecular and Cellular Endocrinology, vol. 349, no. 1, pp. 68-75, 2012.

[11] M. L. Dubocovich, P. Delagrange, D. N. Krause, D. Sugden, D. P. Cardinali, and J. Olcese, "International union of basic and clinical pharmacology. LXXV. Nomenclature, classification, and pharmacology of G protein-coupled melatonin receptors," Pharmacological Reviews, vol. 62, no. 3, pp. 343-380, 2010.

[12] M. Serón-Ferré, M. L. Forcelledo, C. Torres-Farfan et al., "Impact of chronodisruption during primate pregnancy on the maternal and newborn temperature rhythms," PLOS ONE, vol. 8, no. 2, Article ID e57710, 2013.

[13] J. Malek, K. Suk, M. Brestak, and V. Maly, "Daily rhythm of leukocytes, blood pressure, pulse rate, and temperature during pregnancy.," Annals of the New York Academy of Sciences, vol. 98, pp. 1018-1041, 1962.

[14] M. Barr Jr., "Prenatal growth of Wistar rats: circadian periodicity of fetal growth late in gestation," Teratology, vol. 7, no. 3, pp. 283-288, 1973.

[15] M. A. Morgan, S. L. Silavin, R. A. Wentworth et al., "Different patterns of myometrial activity and $24-\mathrm{H}$ rhythms in myometrial contractility in the gravid baboon during the second half of pregnancy," Biology of Reproduction, vol. 46, no. 6, pp. 11581164, 1992.

[16] M. Vatish, P. J. Steer, A. M. Blanks, M. Hon, and S. Thornton, "Diurnal variation is lost in preterm deliveries before 28 weeks of gestation," BJOG: An International Journal of Obstetrics and Gynaecology, vol. 117, no. 6, pp. 765-767, 2010.

[17] J. Malek, J. Gleich, and V. Maly, "Characteristics of the daily rhythm of menstruation and labor.," Annals of the New York Academy of Sciences, vol. 98, pp. 1042-1055, 1962.

[18] H. Takayama, Y. Nakamura, H. Tamura et al., "Pineal gland (melatonin) affects the parturition time, but not luteal function and fetal growth, in pregnant rats," Endocrine Journal, vol. 50, no. 1, pp. 37-43, 2003.
[19] C. K. Ratajczak, M. Asada, G. C. Allen et al., "Generation of myometrium-specific Bmall knockout mice for parturition analysis," Reproduction, Fertility and Development, vol. 24, no. 5, pp. 759-767, 2012.

[20] C. A. Ducsay and S. M. Yellon, "Photoperiod regulation of uterine activity and melatonin rhythms in the pregnant rhesus macaque," Biology of Reproduction, vol. 44, no. 6, pp. 967-974, 1991.

[21] Y. Maeda, M. Muro, M. Shono, H. Shono, and T. Iwasaka, "Diurnal rhythms in fetal heart rate baseline and sustained fetal tachycardia in twin pregnancy," Early Human Development, vol. 82, no. 10, pp. 637-644, 2006.

[22] L. Díaz-Cueto, J. P. Méndez, J. Barrios-de-Tomasi et al., "Amplitude regulation of episodic release, in vitro biological to immunological ratio, and median charge of human chorionic gonadotropin in pregnancy," Journal of Clinical Endocrinology and Metabolism, vol. 78, no. 4, pp. 890-897, 1994.

[23] S. T. Nakajima, T. Mcauliffe, and M. Gibson, "The 24-hour pattern of the levels of serum progesterone and immunoreactive human chorionic Gonadotropin in Normal Early Pregnancy," Journal of Clinical Endocrinology and Metabolism, vol. 71, no. 2, pp. 345-353, 1990.

[24] C. K. Lee, D. H. Moon, C. S. Shin et al., "Circadian expression of $\mathrm{Mel}_{1 a}$ and PL-II genes in placenta: effects of melatonin on the PL-II gene expression in the rat placenta," Molecular and Cellular Endocrinology, vol. 200, no. 1-2, pp. 57-66, 2003.

[25] M. C. Moore-Ede, "Physiology of the circadian timing system: predictive versus reactive homeostasis," The American Journal of Physiology-Regulatory Integrative and Comparative Physiology, vol. 250, no. 5, part 2, pp. R737-R752, 1986.

[26] I. Edery, "Circadian rhythms in a nutshell," Physiol Genomics, vol. 3, no. 2, pp. 59-74, 2000.

[27] C.-M. Hsu, S.-F. Lin, C.-T. Lu, P.-M. Lin, and M.-Y. Yang, "Altered expression of circadian clock genes in head and neck squamous cell carcinoma," Tumor Biology, vol. 33, no. 1, pp. 149$155,2012$.

[28] E. S. Schernhammer, F. Laden, F. E. Speizer et al., "Rotating night shifts and risk of breast cancer in women participating in the nurses' health study," Journal of the National Cancer Institute, vol. 93, no. 20, pp. 1563-1568, 2001.

[29] T. J. Varcoe, N. Wight, A. Voultsios, M. D. Salkeld, and D. J. Kennaway, "Chronic phase shifts of the photoperiod throughout pregnancy programs glucose intolerance and insulin resistance in the rat," PLoS ONE, vol. 6, no. 4, Article ID e18504, 2011.

[30] F. J. Valenzuela, C. Torres-Farfan, H. G. Richter et al., "Clock gene expression in adult primate suprachiasmatic nuclei and adrenal: is the adrenal a peripheral clock responsive to melatonin?" Endocrinology, vol. 149, no. 4, pp. 1454-1461, 2008.

[31] J. C. Dunlap, J. J. Loros, Y. Liu, and S. K. Crosthwaite, "Eukaryotic circadian systems: cycles in common," Genes to Cells, vol. 4, no. 1, pp. 1-10, 1999.

[32] K. Bae, X. Jin, E. S. Maywood, M. H. Hastings, S. M. Reppert, and D. R. Weaver, "Differential functions of mPer1, mPer2, and $m P e r 3$ in the SCN circadian clock," Neuron, vol. 30, no. 2, pp. 525-536, 2001.

[33] M. Akashi, Y. Tsuchiya, T. Yoshino, and E. Nishida, "Control of intracellular dynamics of mammalian period proteins by casein kinase I epsilon (CKIepsilon) and CKIdelta in cultured cells," Molecular and Cellular Biology, vol. 22, no. 6, pp. 1693-1703, 2002. 
[34] M. Stratmann and U. Schibler, "Properties, entrainment, and physiological functions of mammalian peripheral oscillators," Journal of Biological Rhythms, vol. 21, no. 6, pp. 494-506, 2006.

[35] G. A. Lincoln, H. Andersson, and D. Hazlerigg, "Clock genes and the long-term regulation of prolactin secretion: evidence for a photoperiod/circannual timer in the pars tuberalis," Journal of Neuroendocrinology, vol. 15, no. 4, pp. 390-397, 2003.

[36] H. Dardente, J. S. Menet, V.-J. Poirel et al., "Melatonin induces Cry1 expression in the pars tuberalis of the rat," Molecular Brain Research, vol. 114, no. 2, pp. 101-106, 2003.

[37] D. R. Lemos, J. L. Downs, and H. F. Urbanski, “Twenty-fourhour rhythmic gene expression in the rhesus macaque adrenal gland," Molecular Endocrinology, vol. 20, no. 5, pp. 1164-1176, 2006.

[38] C. Campino, F. J. Valenzuela, C. Torres-Farfan et al., "Melatonin exerts direct inhibitory actions on ACTH responses in the human adrenal gland," Hormone and Metabolic Research, vol. 43, no. 5, pp. 337-342, 2011.

[39] C. Torres-Farfan, V. Rocco, C. Monsó et al., "Maternal melatonin effects on clock gene expression in a nonhuman primate fetus," Endocrinology, vol. 147, no. 10, pp. 4618-4626, 2006.

[40] C. Torres-Farfan, N. Mendez, L. Abarzua-Catalan, N. Vilches, G. J. Valenzuela, and M. Seron-Ferre, "A circadian clock entrained by melatonin is ticking in the rat fetal adrenal," Endocrinology, vol. 152, no. 5, pp. 1891-1900, 2011.

[41] H. Oster, S. Damerow, S. Kiessling et al., “The circadian rhythm of glucocorticoids is regulated by a gating mechanism residing in the adrenal cortical clock," Cell Metabolism, vol. 4, no. 2, pp. 163-173, 2006.

[42] M. D. Wharfe, P. J. Mark, and B. J. Waddell, "Circadian variation in placental and hepatic clock genes in rat pregnancy," Endocrinology, vol. 152, no. 9, pp. 3552-3560, 2011.

[43] S. Akiyama, H. Ohta, S. Watanabe et al., "The uterus sustains stable biological clock during pregnancy," The Tohoku Journal of Experimental Medicine, vol. 221, no. 4, pp. 287-298, 2010.

[44] E. Frigato, L. Lunghi, M. E. Ferretti, C. Biondi, and C. Bertolucci, "Evidence for circadian rhythms in human trophoblast cell line that persist in hypoxia," Biochemical and Biophysical Research Communications, vol. 378, no. 1, pp. 108-111, 2009.

[45] A. Balsalobre, L. Marcacci, and U. Schibler, "Multiple signaling pathways elicit circadian gene expression in cultured Rat-1 fibroblasts," Current Biology, vol. 10, no. 20, pp. 1291-1294, 2000.

[46] S. Xiang, L. Mao, T. Duplessis et al., "Oscillation of clock and clock controlled genes induced by serum shock in human breast epithelial and breast cancer cells: regulation by melatonin," Breast Cancer: Basic and Clinical Research, vol. 6, no. 1, pp. 137150, 2012.

[47] A. Balsalobre, F. Damiola, and U. Schibler, "A serum shock induces circadian gene expression in mammalian tissue culture cells," Cell, vol. 93, no. 6, pp. 929-937, 1998.

[48] F. J. Valenzuela, A. Pérez-Sepúlveda, M. J. Torres, P. Correa, G. M. Repetto, and S. E. Illanes, "Pathogenesis of preeclampsia: the genetic component," Journal of Pregnancy, vol. 2012, Article ID 632732, 8 pages, 2012.

[49] P. J. Dutton, L. K. Warrander, S. A. Roberts et al., "Predictors of poor perinatal outcome following maternal perception of reduced fetal movements-a prospective cohort study," PLoS ONE, vol. 7, no. 7, Article ID e39784, 2012.

[50] R. V. Anthony, S. L. Pratt, R. Liang, and M. D. Holland, "Placental-fetal hormonal interactions: impact on fetal growth," Journal of Animal Science, vol. 73, no. 6, pp. 1861-1871, 1995.
[51] Y. Wang and S. Zhao, Vascular Biology of the Placenta, Morgan \& Claypool Life Sciences, San Rafael, Calif, USA, 2010.

[52] S. Koyanagi, Y. Kuramoto, H. Nakagawa et al., "A molecular mechanism regulating circadian expression of vascular endothelial growth factor in tumor cells," Cancer Research, vol. 63, no. 21, pp. 7277-7283, 2003.

[53] A. L. Tranquilli, A. Turi, S. R. Giannubilo, and E. Garbati, "Circadian melatonin concentration rhythm is lost in pregnant women with altered blood pressure rhythm," Gynecological Endocrinology, vol. 18, no. 3, pp. 124-129, 2004.

[54] H. Guo, J. M. Brewer, M. N. Lehman, and E. L. Bittman, "Suprachiasmatic regulation of circadian rhythms of gene expression in hamster peripheral organs: effects of transplanting the pacemaker," The Journal of Neuroscience, vol. 26, no. 24, pp. 6406-6412, 2006.

[55] D. Lanoix, R. Ouellette, and C. Vaillancourt, "Expression of melatoninergic receptors in human placental choriocarcinoma cell lines," Human Reproduction, vol. 21, no. 8, pp. 1981-1989, 2006.

[56] S. R. Pandi-Perumal, V. Srinivasan, G. J. M. Maestroni, D. P. Cardinali, B. Poeggeler, and R. Hardeland, "Melatonin: nature's most versatile biological signal?” FEBS Journal, vol. 273, no. 13, pp. 2813-2838, 2006.

[57] A. Galano, D. X. Tan, and R. J. Reiter, "Melatonin as a natural ally against oxidative stress: a physicochemical examination," Journal of Pineal Research, vol. 51, no. 1, pp. 1-16, 2011.

[58] R. J. Reiter, D.-X. Tan, L. C. Manchester, S. D. Paredes, J. C. Mayo, and R. M. Sainz, "Melatonin and reproduction revisited," Biology of Reproduction, vol. 81, no. 3, pp. 445-456, 2009.

[59] H. G. Richter, J. A. Hansell, S. Raut, and D. A. Giussani, "Melatonin improves placental efficiency and birth weight and increases the placental expression of antioxidant enzymes in undernourished pregnancy," Journal of Pineal Research, vol. 46, no. 4, pp. 357-364, 2009.

[60] C. H. Kim and Y.-M. Yoo, "Melatonin induces apoptotic cell death via p53 in LNCaP cells," Korean Journal of Physiology and Pharmacology, vol. 14, no. 6, pp. 365-369, 2010.

[61] S. M. Dupré, D. W. Burt, R. Talbot et al., "Identification of melatonin-regulated genes in the ovine pituitary pars tuberalis, a target site for seasonal hormone control," Endocrinology, vol. 149, no. 11, pp. 5527-5539, 2008.

[62] E. H. Sharman, S. C. Bondy, K. G. Sharman, D. Lahiri, C. W. Cotman, and V. M. Perreau, "Effects of melatonin and age on gene expression in mouse CNS using microarray analysis," Neurochemistry International, vol. 50, no. 2, pp. 336-344, 2007.

[63] E. Ha, E. Han, H. J. Park et al., "Microarray analysis of transcription factor gene expression in melatonin-treated human peripheral blood mononuclear cells," Journal of Pineal Research, vol. 40, no. 4, pp. 305-311, 2006.

[64] W. Wisessmith, P. Phansuwan-Pujito, P. Govitrapong, and B. Chetsawang, "Melatonin reduces induction of Bax, caspase and cell death in methamphetamine-treated human neuroblastoma SH-SY5Y cultured cells," Journal of Pineal Research, vol. 46, no. 4, pp. 433-440, 2009.

[65] K. Tsutsui, S. Haraguchi, K. Inoue et al., "Identification, biosynthesis, and function of $7 \alpha$-hydroxypregnenolone, a new key neurosteroid controlling locomotor activity, in nonmammalian vertebrates," Annals of the New York Academy of Sciences, vol. 1163, pp. 308-315, 2009. 
[66] K. Ganguly and S. Swarnakar, "Induction of matrix metalloproteinase- 9 and -3 in nonsteroidal anti-inflammatory druginduced acute gastric ulcers in mice: regulation by melatonin," Journal of Pineal Research, vol. 47, no. 1, pp. 43-55, 2009.

[67] F. J. Valenzuela, H. E. Reynolds, C. Torres-Farfán, G. J. Valenzuela, and M. Serón-Ferré, "Melatonin inhibition of the cortisol response to aCth may be exerted through period circadian protein homolog 1 (Per1)," Revista Chilena de Endocrinología y Diabetes, vol. 5, no. 1, pp. 6-12, 2012.

[68] B. Claustrat, J. Brun, and G. Chazot, "The basic physiology and pathophysiology of melatonin," Sleep Medicine Reviews, vol. 9, no. 1, pp. 11-24, 2005.

[69] C. Ekmekcioglu, "Melatonin receptors in humans: biological role and clinical relevance," Biomedicine and Pharmacotherapy, vol. 60 , no. 3, pp. 97-108, 2006.

[70] J. D. Johnston, B. B. Tournier, H. Andersson, M. Masson-Pévet, G. A. Lincoln, and D. G. Hazlerigg, "Multiple effects of melatonin on rhythmic clock gene expression in the mammalian pars tuberalis," Endocrinology, vol. 147, no. 2, pp. 959-965, 2006.

[71] D. Lanoix, P. Guérin, and C. Vaillancourt, "Placental melatonin production and melatonin receptor expression are altered in preeclampsia: new insights into the role of this hormone in pregnancy," Journal of Pineal Research, vol. 53, no. 4, pp. 417425, 2012.

[72] R. Milczarek, A. Hallmann, E. Sokołowska, K. Kaletha, and J. Klimek, "Melatonin enhances antioxidant action of $\alpha$ tocopherol and ascorbate against NADPH- and iron-dependent lipid peroxidation in human placental mitochondria," Journal of Pineal Research, vol. 49, no. 2, pp. 149-155, 2010.

[73] R. Nagai, K. Watanabe, A. Wakatsuki et al., "Melatonin preserves fetal growth in rats by protecting against ischemia/ reperfusion-induced oxidative/nitrosative mitochondrial damage in the placenta," Journal of Pineal Research, vol. 45, no. 3, pp. 271-276, 2008.

[74] C. O. Lemley, A. M. Meyer, L. E. Camacho et al., "Melatonin supplementation alters uteroplacental hemodynamics and fetal development in an ovine model of intrauterine growth restriction," The American Journal of Physiology-Regulatory Integrative and Comparative Physiology, vol. 302, no. 4, pp. R454-R467, 2012.

[75] A. S. Thakor, E. A. Herrera, M. Serón-Ferré, and D. A. Giussani, "Melatonin and vitamin C increase umbilical blood flow via nitric oxide-dependent mechanisms," Journal of Pineal Research, vol. 49, no. 4, pp. 399-406, 2010.

[76] P. Shukla, C. O. Lemley, N. Dubey, A. M. Meyer, S. T. O’Rourke, and K. A. Vonnahme, "Effect of maternal nutrient restriction and melatonin supplementation from mid to late gestation on vascular reactivity of maternal and fetal placental arteries," Placenta, vol. 35, no. 7, pp. 461-466, 2014.

[77] M. J. Perez, B. Castaño, J. M. Gonzalez-Buitrago, and J. J. G. Marin, "Multiple protective effects of melatonin against maternal cholestasis-induced oxidative stress and apoptosis in the rat fetal liver-placenta-maternal liver trio," Journal of Pineal Research, vol. 43, no. 2, pp. 130-139, 2007.

[78] Y. Okatani, A. Wakatsuki, K. Shinohara, C. Kaneda, and T. Fukaya, "Melatonin stimulates glutathione peroxidase activity in human chorion," Journal of Pineal Research, vol. 30, no. 4, pp. 199-205, 2001.

[79] V. Sivakumar, J. Lu, E. A. Ling, and C. Kaur, "Vascular endothelial growth factor and nitric oxide production in response to hypoxia in the choroid plexus in neonatal brain," Brain Pathology, vol. 18, no. 1, pp. 71-85, 2008.

[80] C. Kaur, V. Sivakumar, Y. Zhang, and E. A. Ling, "Hypoxiainduced astrocytic reaction and increased vascular permeability in the rat cerebellum," Glia, vol. 54, no. 8, pp. 826-839, 2006.

[81] C. Kaur, V. Sivakumar, J. Lu, F. R. Tang, and E. A. Ling, "Melatonin attenuates hypoxia-induced ultrastructural changes and increased vascular permeability in the developing hippocampus," Brain Pathology, vol. 18, no. 4, pp. 533-547, 2008.

[82] C. Kaur, V. Sivakumar, and E. A. Ling, "Melatonin protects periventricular white matter from damage due to hypoxia," Journal of Pineal Research, vol. 48, no. 3, pp. 185-193, 2010.

[83] M. Dai, P. Cui, M. Yu, J. Han, H. Li, and R. Xiu, "Melatonin modulates the expression of VEGF and HIF- $1 \alpha$ induced by $\mathrm{CoCl}_{2}$ in cultured cancer cells," Journal of Pineal Research, vol. 44, no. 2, pp. 121-126, 2008.

[84] M. P. Ramírez-Fernández, J. L. Calvo-Guirado, J. E.-M. S. de-Val et al., "Melatonin promotes angiogenesis during repair of bone defects: a radiological and histomorphometric study in rabbit tibiae," Clinical Oral Investigations, vol. 17, no. 1, pp. 147-158, 2013.

[85] K.-J. Kim, J.-S. Choi, I. Kang, K.-W. Kim, C.-H. Jeong, and J.W. Jeong, "Melatonin suppresses tumor progression by reducing angiogenesis stimulated by HIF-1 in a mouse tumor model," Journal of Pineal Research, vol. 54, no. 3, pp. 264-270, 2013.

[86] V. Alvarez-García, A. González, C. Martínez-Campa, C. Alonso-González, and S. Cos, "Melatonin modulates aromatase activity and expression in endothelial cells," Oncology Reports, vol. 29, no. 5, pp. 2058-2064, 2013.

[87] V. Alvarez-García, A. González, C. Alonso-González, C. Martínez-Campa, and S. Cos, "Regulation of vascular endothelial growth factor by melatonin in human breast cancer cells," Journal of Pineal Research, vol. 54, no. 4, pp. 373-380, 2013.

[88] D. Lanoix, H. Beghdadi, J. Lafond, and C. Vaillancourt, "Human placental trophoblasts synthesize melatonin and express its receptors," Journal of Pineal Research, vol. 45, no. 1, pp. 50-60, 2008.

[89] P. M. Iuvone, G. Tosini, N. Pozdeyev, R. Haque, D. C. Klein, and S. S. Chaurasia, "Circadian clocks, clock networks, arylalkylamine $N$-acetyltransferase, and melatonin in the retina," Progress in Retinal and Eye Research, vol. 24, no. 4, pp. 433-456, 2005.

[90] A. Carrillo-Vico, J. R. Calvo, P. Abreu et al., "Evidence of melatonin synthesis by human lymphocytes and its physiological significance: possible role as intracrine, autocrine, and/or paracrine substance.," The FASEB Journal, vol. 18, no. 3, pp. 537539, 2004.

[91] S. Iwasaki, K. Nakazawa, J. Sakai et al., "Melatonin as a local regulator of human placental function," Journal of Pineal Research, vol. 39, no. 3, pp. 261-265, 2005.

[92] Y. Nakamura, H. Tamura, S. Kashida et al., "Changes of serum melatonin level and its relationship to feto-placental unit during pregnancy," Journal of Pineal Research, vol. 30, no. 1, pp. 29-33, 2001.

[93] H. Tamura, Y. Nakamura, M. P. Terron et al., "Melatonin and pregnancy in the human," Reproductive Toxicology (Elmsford, N.Y.), vol. 25, no. 3, pp. 291-303, 2008.

[94] H. Tamura, H. Takayama, Y. Nakamura, R. J. Reiter, and N. Sugino, "Fetal/placental regulation of maternal melatonin in rats," Journal of Pineal Research, vol. 44, no. 3, pp. 335-340, 2008. 
[95] F. Wierrani, W. Grin, B. Hlawka, A. Kroiss, and W. Grünberger, "Elevated serum melatonin levels during human late pregnancy and labour," Journal of Obstetrics and Gynaecology, vol. 17, no. 5, pp. 449-451, 1997.

[96] A. Carrillo-Vico, P. J. Lardone, J. M. Fernández-Santos et al., "Human lymphocyte-synthesized melatonin is involved in the regulation of the interleukin-2/interleukin-2 receptor system," The Journal of Clinical Endocrinology \& Metabolism, vol. 90, no. 2, pp. 992-1000, 2005. 


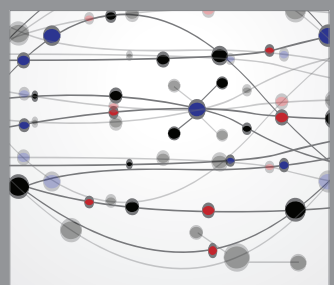

The Scientific World Journal
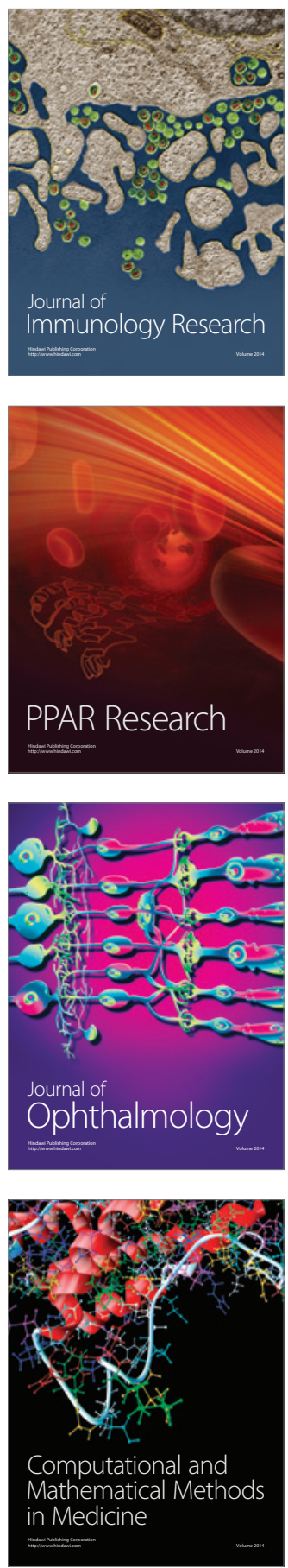

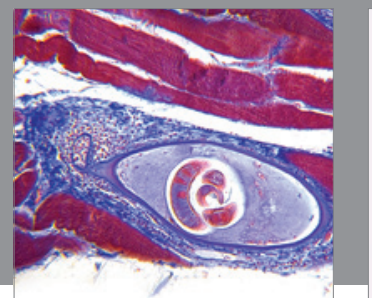

Gastroenterology

Research and Practice
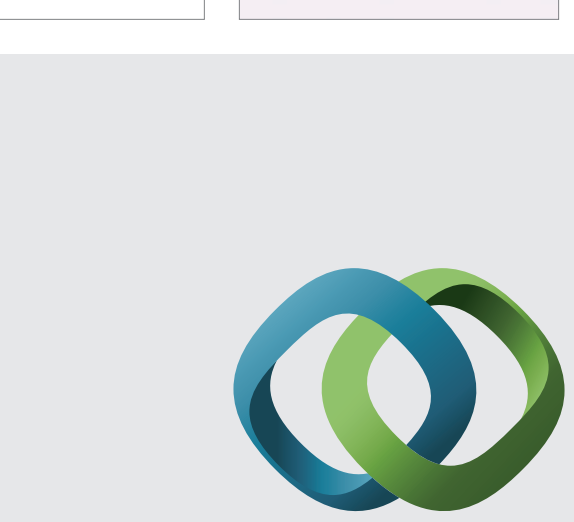

\section{Hindawi}

Submit your manuscripts at

http://www.hindawi.com
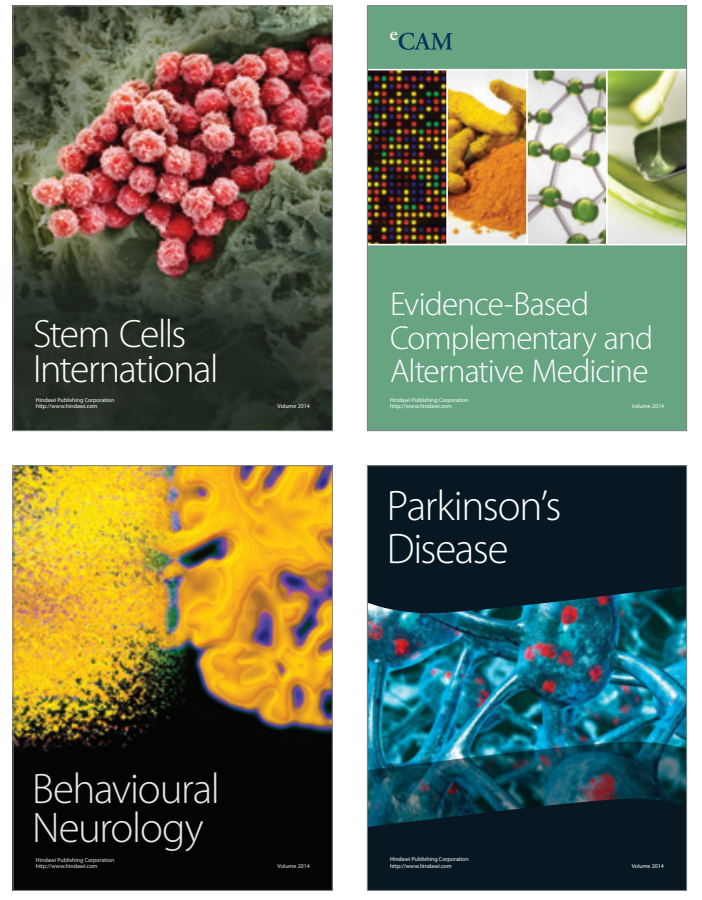
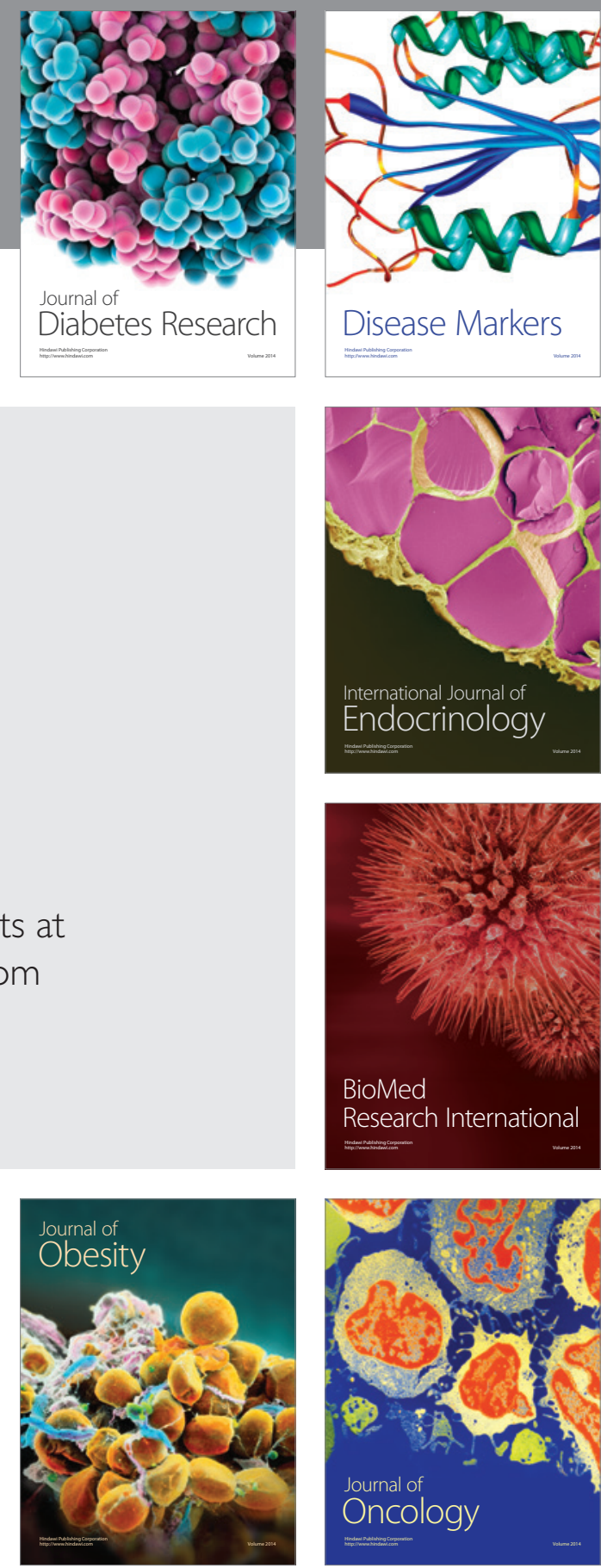

Disease Markers
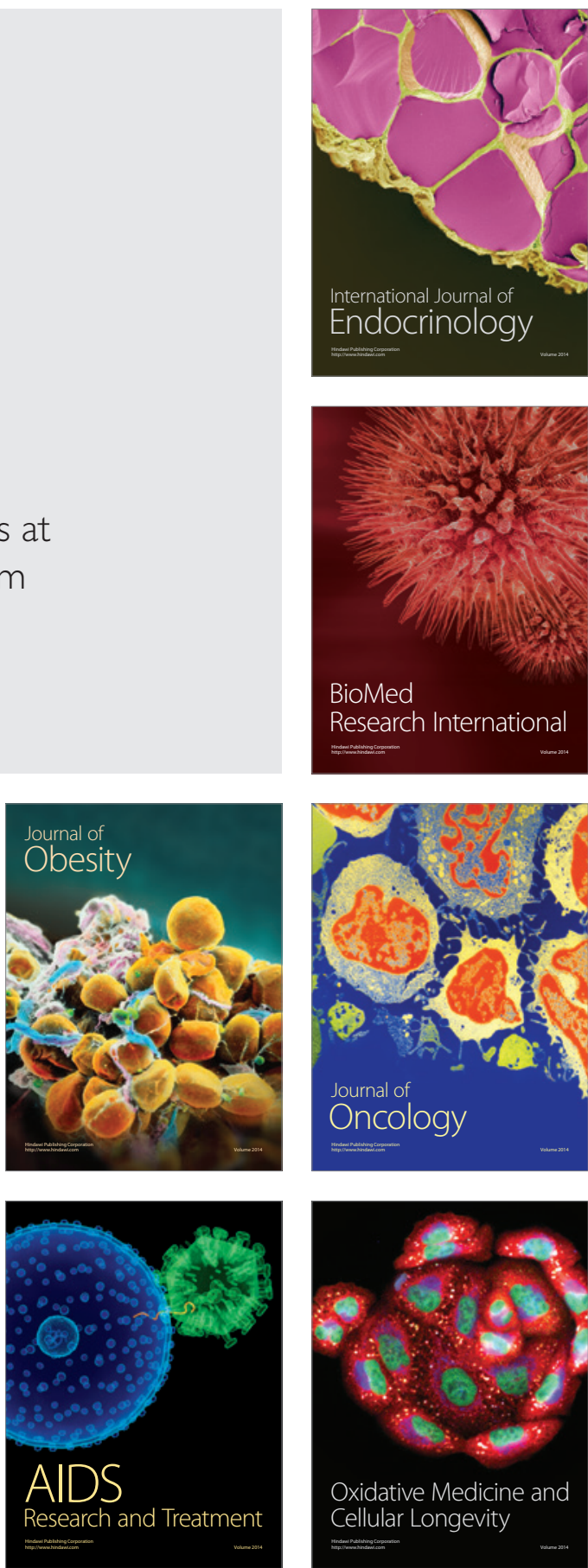